\title{
22. NUEVOS DATOS SOBRE LA PUBLICACIÓN DE SIDERITIS $x$ VALLESII FONT QUER (1924)
}

\author{
Raúl RODRÍGUEZ NOZAL
}

La tradicional preocupación de los farmacéuticos españoles por la botánica ha propiciado la publicación de algunas nuevas especies en revistas de contenido no específicamente botánico, ni siquiera de Historia Natural; nos referimos a la prensa profesional de este colectivo, un medio válido para la descripción de nuevos taxones aunque, en algunas ocasiones, no ha sido tenido suficientemente en cuenta.

La publicación de Sideritis $x$ vallesii Font Quer constituye un ejemplo ilustrativo de este hecho. La bio-bibliografía de P. Font Quer, elaborada por A. Bolòs y O. Bolòs ${ }^{1}$ y las anotaciones posteriores de J.A. Conesa i Mor², recogen un artículo del farmacéutico catalán, publicado en El Restaurador Farmacéutico (Barcelona) bajo el título de «Una nueva Sideritis híbrida de Aragón $»^{3}$, en el que se describe Sideritis $x$ vallesii Font Quer; sin embargo, no mencionan la existencia de otras tres copias de este artículo, con el mismo título, aparecidas en otras revistas profesionales: $L a$ Farmacia Española (Madrid) ${ }^{4}$, El Monitor de la Farmacia y de la Terapéutica (Madrid) ${ }^{5}$ y La Farmacia Moderna (Madrid) ${ }^{6}$.

El artículo publicado en El Restaurador Farmacéutico tiene fecha de 29-II-1924, mientras que los aparecidos en la prensa madrileña vieron la luz en el mes de marzo ( $L a$ Farmacia Española, 15-III-1924; El Monitor de la Farmacia y de la Terapéutica, 20-III1924; La Farmacia Moderna, 25-III-1924); por lo tanto, la publicación válida parece ser la divulgada por la prensa catalana. No parece que las versiones madrileñas sean copia del trabajo editado por el periódico barcelonés, en estas publicaciones era habitual señalar, a pie de página, el orígen del artículo; sin embargo, los cuatro trabajos que nos ocupan son idénticos sin que, a priori, se pueda distinguir el original de las copias. Creemos que pudo ser el propio P. Font Quer quien, en un afán de dar mayor difusión a su trabajo, lo enviase a las principales revistas farmacéuticas profesionales de la época; en las cuatro copias se observa el mismo error tipográfico en la inicial de su nombre, una F. en lugar de la P. de Pío.

\section{NOTAS}

1. A. Bolòs y O. Bolòs. Collectanea Botanica, 7(1): 3-45. 1968

2. J.A. Conesa i Mor. Miscel-lània homenatge al Dr. Pius Font i Quer: 267-291. Lleida, 1988.

3.P. Font Quer. El Restaurador Farmacéutico, 79(4): 77-79. 1924.

4. P. Font Quer. La Farmacia Española, 56(6): 8283. 1924.

5. P. Font Quer. El Monitor de la Farmacia y de la Terapéutica, 972: 86-87. 1924.

6. P. Font Quer. La Farmacia Moderna, 35(6): 92 93. 1924

Aceptado para su publicación en Abril de 1995

Dirección del autor. Departamento de Farmacia y Tecnología Farmacéutica (Historia de la Farmacia). Facultad de Farmacia. Universidad Complutense. 28040, Madrid. 